\title{
BMJ Global Health Shifting the paradigm: using disease outbreaks to build resilient health systems
}

\author{
Kara N Durski (D) , ${ }^{1,2}$ Michael Osterholm, ${ }^{2}$ Suman S Majumdar, ${ }^{3,4}$ Eric Nilles, ${ }^{1}$ \\ Daniel G Bausch, ${ }^{5}$ Rifat Atun (1) ${ }^{6}$
}

To cite: Durski KN, Osterholm M, Majumdar SS, et al. Shifting the paradigm: using disease outbreaks to build resilient health systems. BMJ Global Health 2020;5:e002499. doi:10.1136/ bmjgh-2020-002499

Handling editor Seye Abimbola

Received 16 March 2020 Revised 26 April 2020 Accepted 28 April 2020

Check for updates

(c) Author(s) (or their employer(s)) 2020. Re-use permitted under CC BY-NC. No commercial re-use. See rights and permissions. Published by BMJ.

${ }^{1}$ Harvard Humanitarian Initiative, Harvard T H Chan School of Public Health, Harvard University, Cambridge, Massachusetts, USA

${ }^{2}$ School of Public Health, University of Minnesota, Minneapolis, Minnesota, USA ${ }^{3}$ Burnet Institute, Melbourne, Victoria, Australia

${ }^{4}$ University of Melbourne, Melbourne, Victoria, Australia ${ }^{5}$ UK Public Health Rapid Support Team, Public Health England/ London School of Hygiene \& Tropical Medicine, London, UK ${ }^{6}$ Harvard T H Chan School of Public Health, Harvard University, Boston, Massachusetts, USA

Correspondence to

Kara N Durski;

kdurski@hsph.harvard.edu
Disease outbreaks and health emergencies cause substantial human suffering, death and economic loss. Such events push weak health systems to a breaking point, as witnessed during recent outbreaks of cholera, drugresistant tuberculosis, Ebola virus disease and Zika virus disease. ${ }^{1-4}$ The current COVID-19 pandemic is testing the response and resilience of health systems worldwide, including well-resourced systems in Europe and North America, where health institutions and public health agencies are operating beyond capacity, diagnostics are lacking, triage systems are faltering, personal protective equipment are insufficient, and front-line health workers are facing risks of disease and death. ${ }^{5}$

Building responsive and resilient health systems is an imperative for the global health community. A resilient health system can absorb the shock of an emergency while continuing to provide regular health services. ${ }^{6-8}$ Most frameworks for building resilient health systems that effectively respond to disease outbreaks focus on enhancing preparedness or response capacity prior to an emergency ${ }^{9-11}$ or to strengthen health systems after the emergency, typically during the recovery phase. Indeed, many aspects of outbreak response lay the groundwork for health system strengthening (HSS), such as enhancing surveillance systems and training the health workforce. ${ }^{12}$ Over the last two decades, numerous mechanisms, frameworks and agreements have been developed to promote health systems that are resilient to outbreaks and major health emergencies, such as the International Health Regulations (IHR) - an agreement between 196 countries to work together to mitigate global health security threats and a cornerstone of efforts aimed at ensuring sufficient health system infrastructure to detect, assess and report major events impacting public
Summary box

Disease outbreaks and health emergencies can push health systems to a breaking point, especially fragile systems.

- Building resilient and responsive health systems is an imperative for the global health community and there is an important opportunity to address health systems strengthening activities during outbreak response.

- The resources dedicated to outbreaks create organisational infrastructure, capacity and networks that can be leveraged to simultaneously strengthen health systems.

- It is necessary to shift the current paradigm of managing outbreaks to include health system strengthening as a critical component of the response. We identify 10 activities that could be implemented during health emergencies to achieve this goal.

health. ${ }^{13}$ Through the IHR, in 2016 the Joint External Evaluations were created to identify critical gaps within health systems and prioritise actions to enhance preparedness and response within a country. ${ }^{14}$

There is not yet a framework, toolkit or formalised targets for HSS activities during outbreaks. While these activities are already taking place during response efforts, they are often considered low priority among a host of challenges and/or are given limited financial support. There remains an opportunity to more systematically strengthen health systems during outbreak response (particularly in the early to mid-stages) when there is heightened attention and available resources. Here, we discuss the need for a paradigm shift to include HSS as a key component integrated into outbreak response and provide insights into how this shift can be accomplished, with particularly important implications for the current COVID-19 pandemic.

During outbreaks, ministries of health and other national and international responding 
organisations are routinely provided with financial and/or human resources support by internal or external funding bodies. For example, during the current COVID-19 pandemic the USA approved a US\$2 trillion-dollar stimulus bill, of which US $\$ 157$ billion was directly allocated to the health system and research. ${ }^{15}$ While it is critical and ethically necessary to prioritise immediate response activities, the organisational infrastructure, capacity and networks which typically result from these investments could be leveraged to also strengthen health systems, in particular those components that are directly impacted during the outbreak, such as health information systems, healthcare services, medical and public health workforce, supply chain management and essential medicines and vaccines. Strengthening these components during the acute response may require additional resources but, in the long-term, would likely result in cost-savings when system efficiency and effectiveness improve. This approach would strengthen the health system, promote sustainability of the emergency investment and increase resilience against future emergencies.

An ongoing challenge is to ensure the sustainability of the investments post-response. Lessons could be learned from industries, such as military, nuclear, oil and gas and aviation that have similar high-pressure and complex environments as the biomedically oriented institutions and experience major events and disasters, and have used methodologies to effectively address acute challenges while building better, more sustainable systems and processes along the way. ${ }^{16}$ Methodologies like systems analysis and applied systems thinking could be adapted and used during an acute response to both further enhance response effectiveness and strengthen health systems. ${ }^{16}$

We have identified 10 activities that could be implemented during health emergencies to ensure that health systems are strengthened during the response. While some activities can be applied on subnational and national levels, others may be best suited to regional or international scales.

1. Inclusion of health system experts in Emergency Coordination Centres, or country equivalent, from the onset of the emergency response.

2. Ensuring that response teams, usually and appropriately multidisciplinary, include personnel with the skills to assess and incorporate elements of HSS into the response, such as project managers, data analysts, engineers, and experts in health systems and applied system methodologies.

3. Developing a network and community of thought leaders and/or contributors who can provide support and innovative ideas for HSS during outbreaks. Examples of effective networks in related domains include the $\mathrm{R}$ Epidemics Consortium (www.repidemicsconsortium.org/) and the WHO's Emerging Diseases Clinical Assessment and Response Network (www.who.int/csr/edcarn/en/).
4. Developing a toolkit focused on strengthening health systems during an outbreak, including metrics of health system performance, in order to provide guidance for outbreak response teams to ensure HSS actions are considered as a priority when responding to outbreaks.

5. Developing a cadre of health professionals with expertise in both HSS and outbreak response to integrate these activities.

6. Conducting operational and implementation research during health emergencies to understand which interventions, strategies and tools provide the best outcomes for both the acute response and strengthening of health systems and to facilitate immediate policy relevance and scalability.

7. Adjusting already existing HSS frameworks to provide guidance for outbreak response settings and developing the associated performance metrics.

8. Including funds for HSS in outbreak response budgets. While this would increase short-term costs, these would likely be easily offset by the future gains that strengthened health systems would provide in disease prevention.

9. Targeting communications and advocacy efforts to appeal to political leaders and affected communities, highlighting the importance of health system resilience and the need to focus on associated activities during health emergencies.

10. Aligning outbreak response activities with HSS goals to ensure acute response challenges are met while also ensuring sustainability of efforts.

Several conditions will enable the adoption of such an approach. These include strong national leadership and governance, donor partner and national policies designed to absorb an influx of funds during the response for both acute and long-term system strengthening activities, including the prioritisation of funding to activities that support both activities, good communication and support between the teams involved in the outbreak response and HSS activities, open sharing of data and other relevant information to allow for integrated solutions, and a growth mindset. Furthermore, institutional support and buy-in from partners involved in the response is crucial to ensure that funding is available to sustain the activities both during the acute emergency and afterwards.

Outbreaks which create uncertain, complex and dynamic environments provide an opportunity to adopt systems thinking ${ }^{17}$ and new approaches to simultaneously and effectively strengthen health systems during the response. Furthermore, they serve as catalysts for garnering both political and public support for HSS efforts. The COVID-19 outbreak presents such an opportunity, as critical health system bottlenecks are being exposed in high-income, middle-income and low-income countries alike. In a globalised society in which diseases with epidemic and pandemic potential are increasing, a paradigm shift is needed to ensure that every opportunity 
is used to ensure a rapid, effective response to the current threat while building responsive, resilient and sustainable health systems that keep populations healthy in the long term.

Twitter Kara N Durski @KaraDurski and Rifat Atun @RifatAtun

Acknowledgements We thank Yolana Pollak for her support in editing the manuscript. The UK Public Health Rapid Support Team is funded by UK aid from the Department of Health and Social Care and is jointly run by Public Health England and the London School of Hygiene \& Tropical Medicine. SSM is supported by the Australian Government through a National Health and Medical Research Council Postgraduate Scholarship and the Stronger Systems for Health Security Programme (Grant 1152867).

Contributors All authors provided significant contributions to the writing and editing of the manuscript.

Funding The authors have not declared a specific grant for this research from any funding agency in the public, commercial or not-for-profit sectors.

Disclaimer The views expressed in this publication are those of the authors and not necessarily those of the National Health Service, the National Institute for Health Research, the Department of Health and Social Care or Australian Government.

Competing interests None declared.

Patient consent for publication Not required.

Provenance and peer review Not commissioned; externally peer reviewed.

Data availability statement The authors confirm that the data supporting the findings of this study are available within the article.

Open access This is an open access article distributed in accordance with the Creative Commons Attribution Non Commercial (CC BY-NC 4.0) license, which permits others to distribute, remix, adapt, build upon this work non-commercially, and license their derivative works on different terms, provided the original work is properly cited, appropriate credit is given, any changes made indicated, and the use is non-commercial. See: http://creativecommons.org/licenses/by-nc/4.0/.

\section{ORCID iDs}

Kara N Durski http://orcid.org/0000-0003-1456-626X

Rifat Atun http://orcid.org/0000-0002-1531-5983

\section{REFERENCES}

1 Kieny MP, Dovlo D. Beyond Ebola: a new agenda for resilient health systems. Lancet 2015;385:91-2.

2 Morris L, Hiasihri S, Chan G, et al. The emergency response to multidrug-resistant tuberculosis in Daru, Western Province, Papua New Guinea, 2014-2017. Public Health Action 2019;9:S4-11.

3 Gates B. The next epidemic--lessons from Ebola. N Engl J Med 2015;372:1381-4.

4 McNeil D. How the response to Zika failed millions, the new York times. Available: https://www.nytimes.com/2017/01/16/health/zikavirus-response.html [Accessed March 2020].

5 Hick JL, Biddinger PD. Novel Coronavirus and Old Lessons Preparing the Health System for the Pandemic. N Engl J Med 2020. doi:10.1056/NEJMp2005118. [Epub ahead of print: 25 Mar 2020]

6 Massuda A, Hone T, Leles FAG, et al. The Brazilian health system at crossroads: progress, crisis and resilience. BMJ Glob Health 2018;3:e000829.

7 Ammar W, Kdouh O, Hammoud R, et al. Health system resilience: Lebanon and the Syrian refugee crisis. J Glob Health 2016;6:020704

8 Fukuma S, Ahmed S, Goto R, et al. Fukushima after the great East Japan earthquake: lessons for developing responsive and resilient health systems. J Glob Health 2017;7:010501.

9 Blanchet K, Nam SL, Ramalingam B, et al. Governance and capacity to manage resilience of health systems: towards a new conceptual framework. Int J Health Policy Manag 2017;6:431-5.

10 Nicholson A, Reeve Snair M, Hermann J. Global health risk framework: resilient and sustainable health systems to respond to global infectious disease outbreaks: workshop summary. Washington (DC): National Academies Press, 2016.

11 Kruk ME, Myers M, Varpilah ST, et al. What is a resilient health system? Lessons from Ebola. Lancet 2015;385:1910-2.

12 WHO. Recovery toolkit: supporting countries to achieve health service resilience. World Health organization, 2016. Available: http:// www.who.int/csr/resources/publications/ebola/recovery-toolkit/en/ [Accessed March 2020].

13 WHO. Strengthening health security by implementing the International health regulations. World Health organization. Available: http://www.who.int/ihr/about/en/ [Accessed March 2020].

14 WHO. Joint external evaluation tool (JEE tool) -. second edition. World Health Organization, 2018. http://www.who.int/ihr/ publications/WHO_HSE_GCR_2018_2/en/. (accessed March 2020).

15 Investopedia. Government stimulus efforts to fight the COVID-19. Crisis 2020.

16 Bar-Yam Y. Complexity of military conflict: multiscale complex systems analysis of littoral warfare. New England complex systems Institute, 2003. Available: http://citeseerx.ist.psu.edu/viewdoc/ download?doi=10.1.1.132.6248\&rep=rep1\&type=pdf

17 Coker R, Atun RA, McKee M. Health systems and communicable disease control. Berkshire, England: McGraw Hill, Open University Press, 2008. 